\title{
Pest diagnosis expert system on chili plants using Forward Chaining method in the department of agriculture in Pagar Alam City
}

\author{
Evy Septriani*, Yogi Isro Mukti \\ Program Studi Teknik Informatika Sekolah Tinggi Teknologi Pagar Alam \\ Email Korespondensi: "Evyseptriani05@ gmail.com
}

\begin{abstract}
This study aims to produce an expert system for diagnosing pests in chilies using the Forward Chaining method. Chili is one of the basic needs of the community as a flavoring or flavor, but farmers often experience failure to harvest due to pest attacks on chili plants. The system development method used by Waterfall consists of four stages, namely Analysis, Design, Coding and Testing. Therefore, the researcher created an expert system for diagnosing pests in chilies using the Onlane Forward Chaining method. the benefits of this expert system for the city of Pagar Alam, especially for farmers, make it easy to find out the types of pests that attack and provide solutions to prevent pests from being planted in chilies like an expe
\end{abstract}

Keywords: Expert system; Chili; Forward Chaining; Waterfall

\section{Pendahuluan}

Perkembangan Teknologi yang begitu pesat, banyak memberikan pengaruh terhadap perkembanagn berbagai sektor, dan salah satunya adalah sektor pertanian dimana semakin banyak teknologi yang dikembangkan untuk digunakan agar mempermudah banyak perkerjaan di bidang pertanian, dimana banyak peralatan pertanian yang dikembangkan sehingga proses perkerjaan pertanian dapat diselesaikan dengan baik dan memberikan hasil yang lebih baik.

Salah satu teknologi yang banyak dikembangkan adalah teknologi yang mamapu untuk mengadopsi proses dan cara berfikir manusia yaitu teknologi kecerdasan buatan Artificial Intelligence merupakan salah satu ilmu komputer yang berperilaku cerdas seperti manusia. Di sisi lain, sistem pakar adalah salah satu cabang dari kecerdasan buatan yang menggunakan pengetahuan khusus yang dimiliki seorang ahli untuk memecahkan suatu masalah tertentu. [1]Didalam sistem pakar terdapat beberapa metode yang digunakan diantaranya Forward Chaining, merupakan salah satu metode yang membutukan suatu faktafakta atau data terlebih dahuluuntuk memperoleh suatu informasi.

Cabai merupakan komoditas sayuran yang banyak digunakan oleh masyarakat sebagai penyedap rasa masakan. Selain digunakan untuk bumbu dapur cabai juga digunakan untuk pelengkap makanan ringan. Seiring dengan pertumbuhan produk membuat permintaan terhadap tanaman cabai juga ikut meningkat seakan-akan cabai sudah menjadi kebutuhan pokok masyarakat. Sebagian besar masyarakat kota Pagar 
Alam bermata pencarian sebagai petani salah satunya petani cabai dengan meningkatnya permintaan cabai banyak para petani membudidayakan tanaman ini, karena kegiatan usaha tani pada budidaya tanaman cabai salah satu keuntungan yang menjanjikan dan untuk meningkatkan perekonomian masyarakat Pagar Alam. Akan tetapi pada budidaya tanaman cabai para petani sering mengalami kegagalan salah satunya diakibatkan serangan oleh hama pada tanaman cabai. Hal tersebut dikarenakan kurangnya pengetahuan dan penyuluhan terhadap petani cabai. Sehingga para petani kesulitan untuk mendiagnosa mengenai masalah apa yang sedang terjadi pada tanaman cabai tersebut, maka bukan biaya saja yang diperlukan untuk pembelian pestisida akan tetapi juga mengakibatkan tanaman cabai mati sehingga panen menjadi gagal .

Berdasarkan latar belakang di atas maka dalam penelitian ini akan dibuat Sistem Pakar Diagnosa Hama Pada Tanaman Cabai menggunakan metode Forward Chaining pada Dinas Pertanian Kota Pagar Alam. Dengan adanya sistem pakar ini diharapkan para petani khususnya petani cabai dapat mengakses informasi lebih mudah dan cepat serta dapat digunakan kapanpun dan dimapaun berada tanpa mengenal jarak dan waktu

\section{Metode}

Model SDLC air terjun (waterfall) sering juga disebut model sekuensial linier (sequential linier) atau alur hidup klasik (classic life cycle) model air terjun menyediakan pendekatan alur hidup perangkat lunak secara sekuensial atau terurut dimulai dari analis, desain, pengodean, pengujian, dan tahap pendukung (support). Berikut adalah tahapan pengembanagn model air terjun. [2]

Tahapan Waterfall terdiri dari 4 tahapan,yaitu:

1. Analisis Kebutuhan Perangkat lunak

Proses pengumpulan kebutuhan dilakukan dengan cara intensif untuk mespesifikan kebutuhan perangkat lunak agar didapat dipahami perangkat lunak seperti apa yang dibutuhkan oleh user.

2. Desain

Desain perangkat lunak adalah proses meliputi langkah yang focus pada desain pembuatan program perangkat lunak termasuk struktur data, arsetektur perangkat lunak, representasi antarmuka, dan prosedur pengodean.

3. Pembuatan kode program

Desain harus ditranslasikan ke dalam program perangkat lunak. Hasil dari tahap ini adalah program computer sesuai dengan desain yang telah buat pada tahap desain.

4. Pengujian

Pengujian focus pada perangkat lunak secara diri segi logic dan fungsional dan memastikan bahwa semua bagian sudah uji. Hal ini dilakukan untuk meminimalisir kesalahan (error) dan memastikan keluaran yang dihasilkan sesuai dengan yang diingikan.

5. Pendukung (support) atau pemeliharaan (maintenance)

Tahap pendukung atau pemeliharaan dapat mengulangi proses pengembangan mulai dari analisis spesifikasi untuk perubahan perangkat lunak yang sudah ada, tetapi tidak untuk membuat perangkat lunak baru.

\subsection{Teknik Pengumpulan Data}

Pada penelitian ini dalam rangka pengumpulan data yang diperlukan pada penulisan, penulis menggunakan beberapa metode pengumpulan data, yaitu:

1. Observasi (Pengamatan)

Teknik Observasi merupakan salah satu melakukan pengamatan secara langsung terhadap permasalahan yang ada di objek penelitian. dilakukan untuk proses pendataan kebutuhan untuk Sistem Pakar Diagnosa Hama Pada Tanaman Cabai. 
2. Interview (Wawancara)

Teknik wawancara merupakan salah satu pengumpulan data yang diperoleh dengan cara peneliti melakukan tanya jawab kepada salah satu staf pegawai dinas pertanian Kota Pagar Alam.

3. Studi Pustaka

Metode yang dilakukan dengan mencari bahan yang mendukung dalam mendefinisikan masalah melalui buku-buku, jurnal bahan-bahanyang erat dengan objek permasalahan.

\subsection{Sistem Yang Diusulkan.}

\subsubsection{Use Case Diagram}

Use Case Diagram menggambarkan fongsionalitas yang diharapkan dari sebuah system yang ditekankan adalah "apa" yang diperbuat sistem dan bukan "bagaimana", sebuah use case mempresentasikan sebuah intraksi antara aktor dengan sistem (Rosa A.S,M .(2016) pada sistem pakar ini terdapat tiga aktor yang berperan diantaranya, admin, user dan pakar. Proses use case diagram ini menjadi beberapa bagian yaitu, sebagai berikut:

A. Kegiatan actor sebagai admin adalah melakukan login untuk bisa mengakses sistem pakar ini, dan mengatur sistem pakar ini admin akan dihadapkan beberapa menu diantaranya mengolah master data, data rule, mengolah data regestrasi, mengola data home, mengolah data profil dan mengatur tampilan web sesuai dengan kebutuhan.

B. Kegiatan actor sebagai user pada sistem pakar ini adalah membuka website sistem pakar ini, setelah membuka website ini user bisa melihat beberapa menu diantaranya galeri yang berisi foto atau gambar jenis-jenis hama, menu profil berisi profil Dinas Pertanian Kota Pagar Alam. Dalam website ini user bisa melakukan proses diagnose setelah melewati beberapa proses diantaranya, proses pendaftaran guna untuk mendapatkan username dan password, kemudian login dengan menggunakan username dan password yang telah didapat dari proses pendaftaran tersebut. Setelah user melakukan proses diagnose user akan mendapakan hasil dari proses diagnose saran dan langkah-langkah yang dilakukan selanjutnya.

C. Actor sebagai pakar dalam sistem ini bertugas untuk memberikan informasi tentang beberap jenis hama, gejala dan cara penangananya.

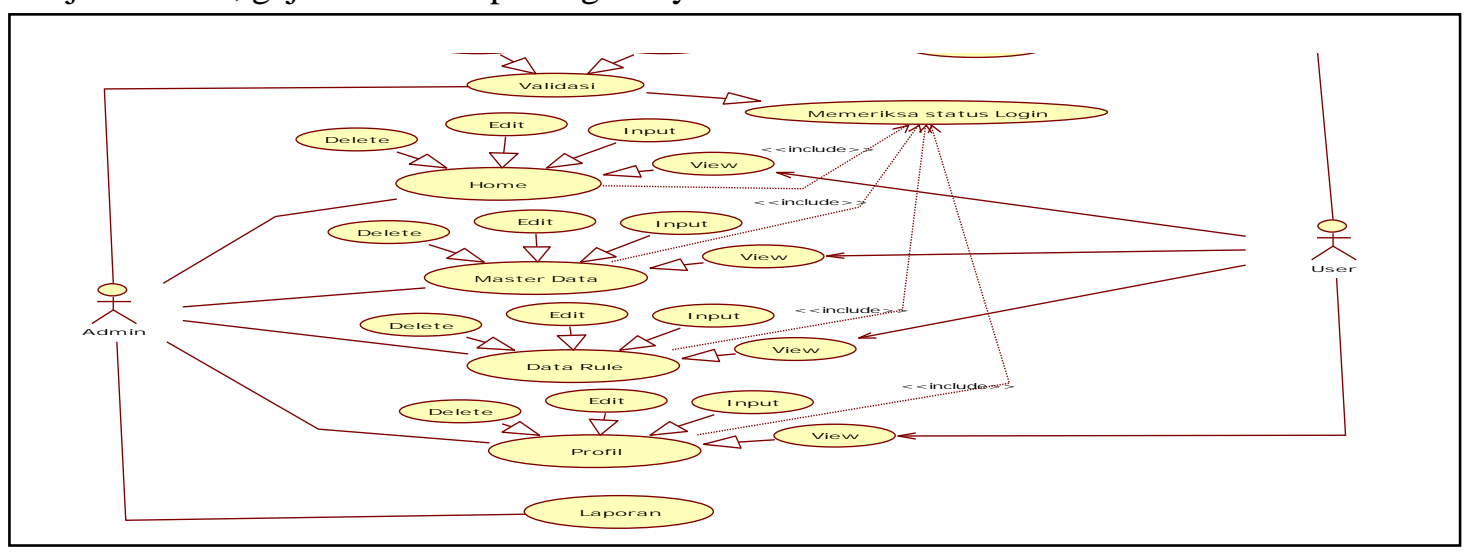

Gambar 1. Use Case Diagram.

\section{Hasil dan Pembahasan}

Dari Penelitian ini telah didapatkan hasil diagnosa hama penyakit tanaman cabai menggunakan metode forward chaining adalah sistem yang yang memberikan informasi mengenai hama tanaman cabai dan agar dapat membantu user untuk mengetahui hama dan yang ada pada tanaman cabai melalui gejala-gejala yang diinputkan ke dalam sistem pakar ini. Untuk mewujudkan sistem pakar yang sesuai digunakan 
metode forward chaining yang menggunakan data-data atau fakta-fakta awal untuk selanjutnya diproses dan akan menghasilkan suatu informasi tentang hama penyakit tanaman cabai. Pemrograman sistem pakar merupakan salah satu perangkat lunak (software) yang digunakan dalam bidang ilmu pengetahuan teknologi. Pada penelitian ini bahasa program yang digunakan berupa bahasa pemrograman $P H P$ dan didukung database MYSQL, Software yang digunakan Web Browser, Xampp, Adobe Dreamweaver, database dan Axure. Pembuatan sistem pakar diagnosa hama penyakit tanaman cabai menggunakan metode forward chaining dilakukan berdasarkan tahap pengembangan sistem metode waterfall yaitu analisis, desain, pembuatan kode program, pengujian dan pendukung (support) atau pemeliharaan (maintenance). Proses pengujian dilakukan untuk mengukur kevalidan sistem dengan pengujian black box testing.

\subsection{Tampilan Halaman Utama}

Halaman utama merupakan halaman awal ketika mengakses web sistem pakar ini. Adapun sub-menu yang terdapat yaitu Home, Profil, Informasi Tanaman Cabai serta terdapat form Login dan Daftar untuk user sebelum login. Berikut ini adalah tampilan halaman utama.

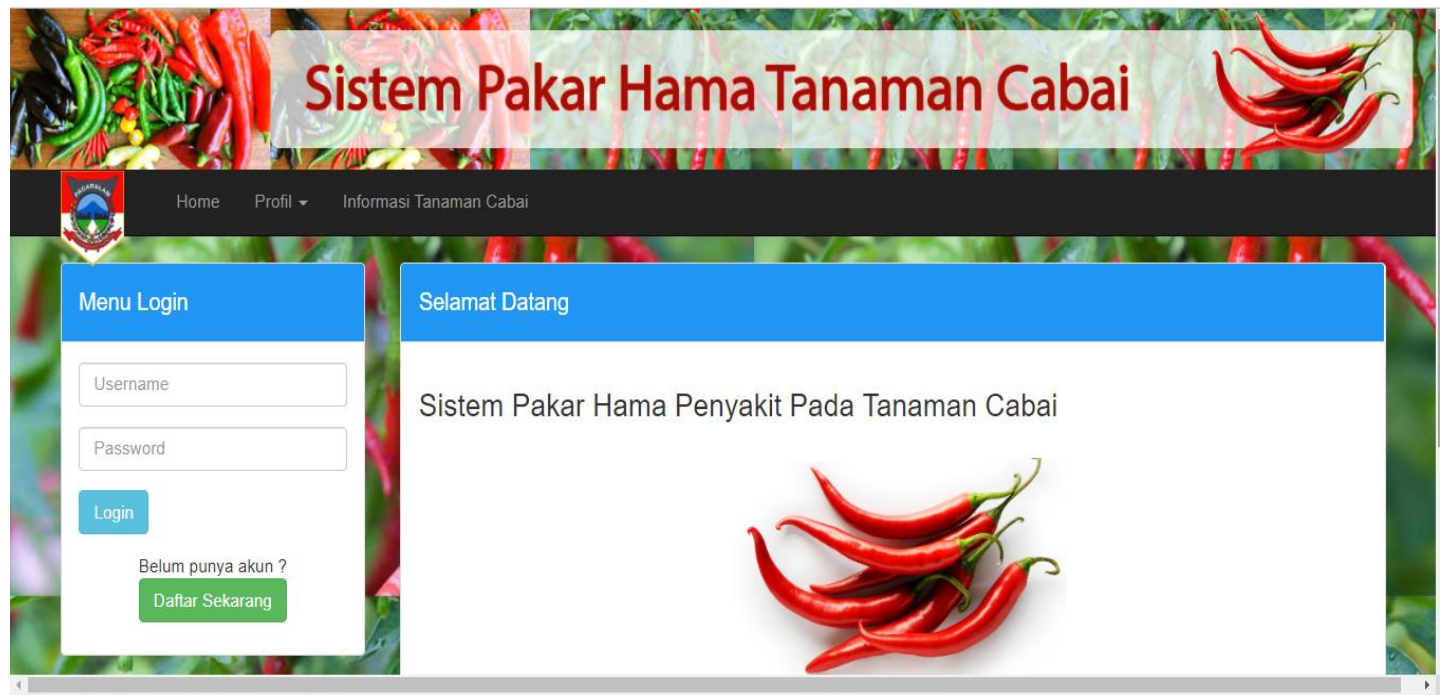

Gambar 2. Gambar halaman utama.

\subsection{Tampilan Halaman Regestrasi}

Menu ini berfungsi bagi user sistem pakar untuk mendapatkan username dan password agar bisa log in sebagai user. Berikut gambar tampilanya.

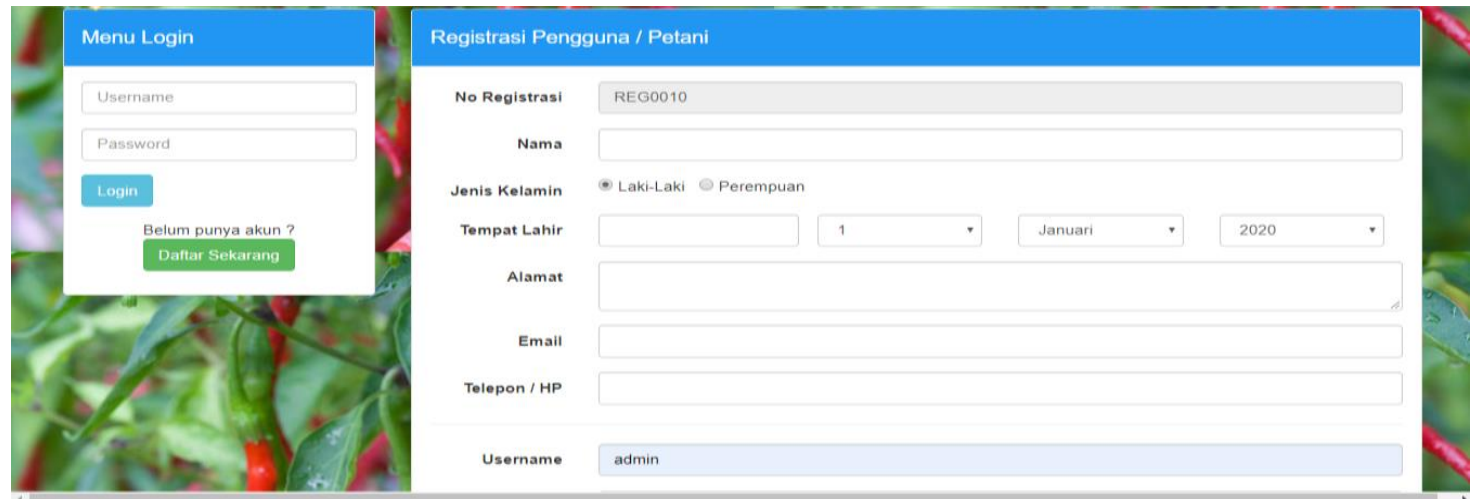

Gambar 3. Gambar Regestrasi. 


\subsection{Tampilan Halaman Login User}

Halaman ini berfungsi untuk login user ke sistem yang berisi username dan password.

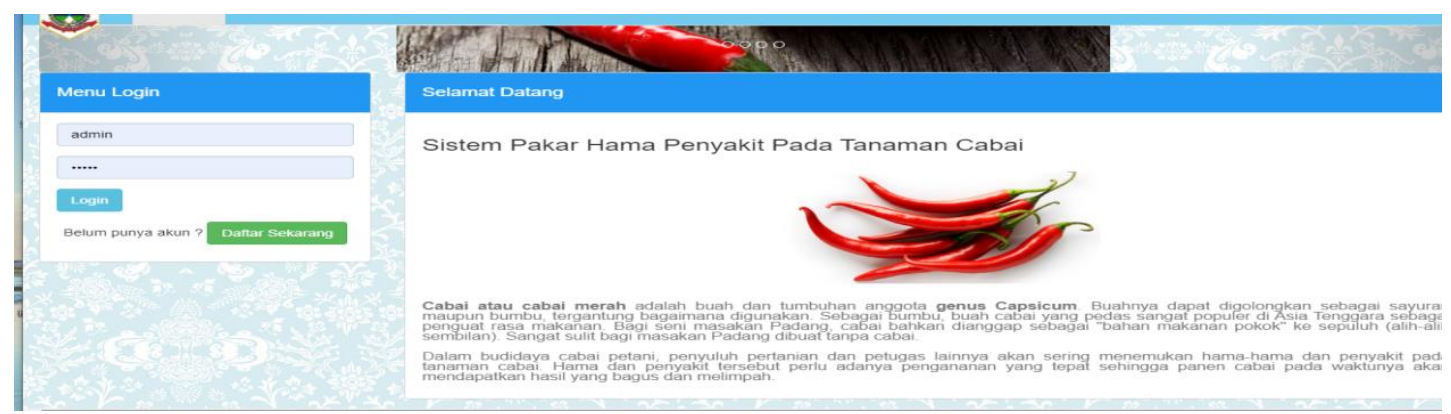

Gambar 4. Gambar Login User

\subsection{Tampilan Halaman Rule Diagnosa}

Halaman ini berfungsi untuk user memilih gejala-gejala Hama pada tanaman Cabai. Berikut ini adalah tampilan halaman Rule Diagnosa.

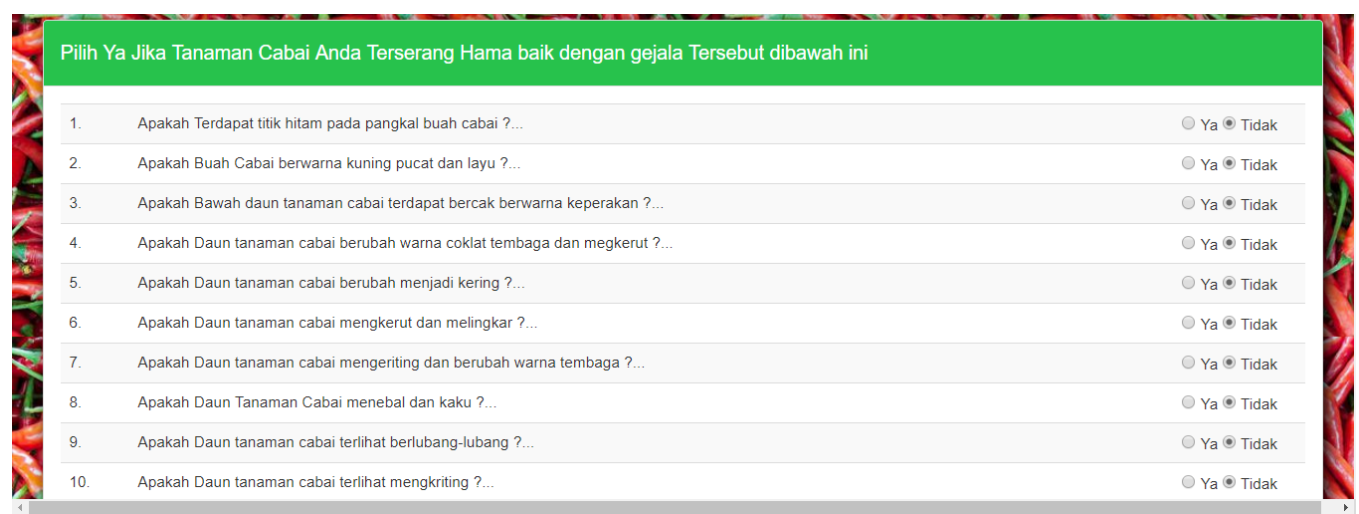

Gambar 5. Gambar Rure Diagnosa

3.5 Tampilan Halaman Hasil Diagnosa

Halaman ini berfungsi sebagai informasi hasil dari diagnose yang telah dilakukan. Berikut ini tampilanya. 


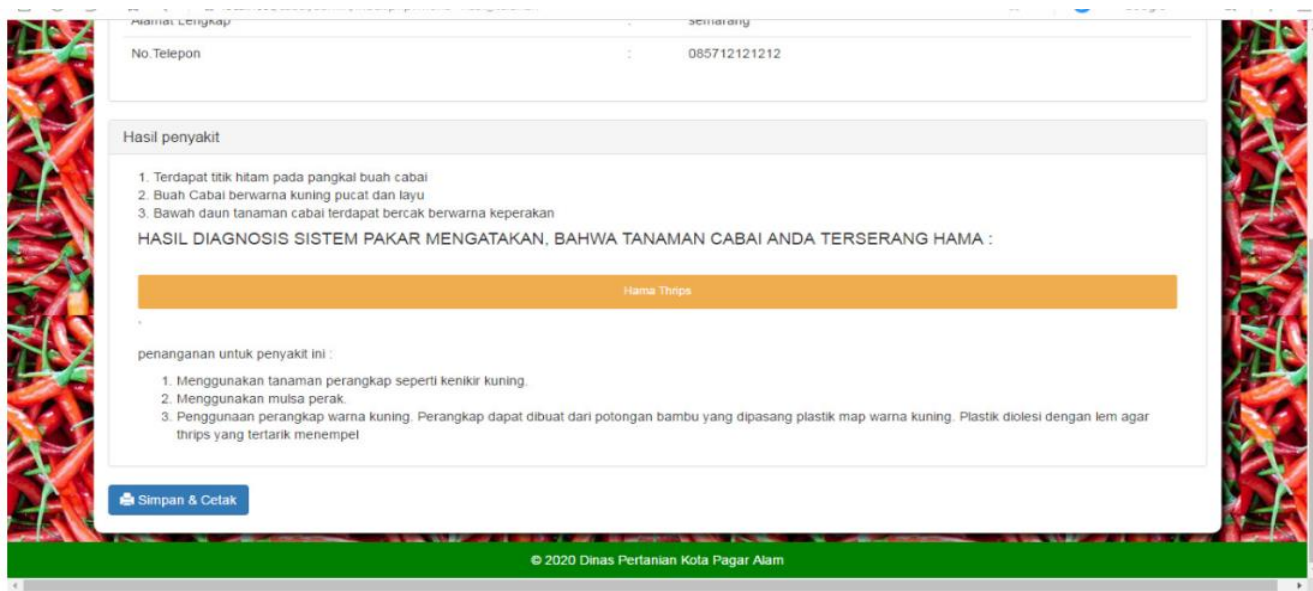

Gambar 6. Gambar Hasil Diagnosa.

\section{Kesimpulan}

Adapun kesimpulam dalam penelitian ini yaitu:

1. Sistem pakar ini dapat memberikan informasi dan diagnose awal untuk hama pada tanaman cabai dan ditampilkan berbsis web dengan bahasa pemrograman $P H P$.

2. Sistem pakar ini dapat dijadikan sebagai media penerapan seorang ahli atau pakar dalam menanaliss dan mendeteksi hama pada tanaman cabai.

5. Ucapan Terimakasih

1. Terima kasih kepada LPPM STT Pagar Alam

2. Panitia Senatik STT Adisucipto Yogyakarta

\section{Daftar Pustaka}

[1] T. Sutojo, Kecerdasan Buatan, Semarang: ANDI, 2010.

[2] R. A. S. M. Shalahudin, Rekayasa Perangkat Lunak, Bandung: Informatika, 2013.

[3] Y. Anindita, "Sistem Pakr Deteksi Hama Dan Penyakit Pada Tanaman Cabai Dengan Metode Naive Bayes," Prosiding Seminar InformatikaAplikatif Polinema, pp. ISSN 2460-1160, 2015.

[4] A. Mahbudi, "Rancang Bangun Sistem Pakar Untuk Mendiagnosis Tanaman Cabai Menggunakan Metode Bayes," Jurnal Rekayasa Dan Manajemen Sitem Informasi, pp. ISSN 2460-8181, 2016.

[5] Z. Azmi, Pengantar Sistem Pakar Dan Metode, Medan: Mitra Wacana Media, 2017.

[6] A. H. R. Darmawan, Budi Daya Cabai Unggul, Jakarta: Penebar Swadaya, 2010.

[7] P. R.S, Rekayasa Perangkat lunak, Yogyakarta: Andi, 2015.

[8] Jaroji, "Sistem Pakar Pedia Pertanian Berbasis Android Dengan Menerapkan Metode Naive Bayes," Jurnal Sistem Informasi, pp. ISSN2303-8149, 2019.

[9] T. Christy, "Implementasi Sitem Pakar Diagnosa Penyakit Cabe Menggunakan Metode Forward Chaining," STIMIK Royal, pp. 353-358, 2018.

[10] Z. Azmi, Pengantar Sistem Pakar Dan Metode, Medan: Mitra Wacana Media, 2017. 